places of all these stars as if they were as accurately determined as fundamental stars should be, because there was not in some cases sufficient material for the determinations of accurate proper motions. It is suggested that after an interval of fifteen to twenty years these stars should be again systematically observed and computed afresh. The catalogue, which is arranged for the epoch I9oo, further contains the values of Bessel's constants computed for that year. There is also added the places of twenty-four stars, lying near the south pole, which have been chosen by Dr. Gill, and observed at the Cape Observatory.

Latitude Observations at the U.S. Naval ObservaTORY, WASHINGTON.-Prof. W. Harkness describes the results of a determination of the latitude, and its observed variation, of the Washington Observatory in the Astronomical Journal (No. 404). The method employed involved the use of two instruments, namely, the transit instrument, of 77 inches focal length and 4.86 inches aperture in the prime vertical, and the meridian instrument of 30 inches focal length and 2.55 inches aperture; the latter could be used either as a transit instrument or as a zenith-telescope. The plan of work adopted was to observe $\alpha$ Lyræe at every possible culmination, both night and day, throughout the year, and also to observe four other stars near the times of their maximum aberration, in order to eliminate the latter constant from the latitude variation. The final result of the investigation is given in a table showing the observed values of the variation of the latitude.

Appearance of D'Arres'r's Conet.-A communication from America informs us that Prof. Holden telegraphs that D'Arrest's comet was observed by Perrine June 28.9764 Greenwich mean time. Apparent R.A. $30^{\circ} 2 \mathrm{I}^{\prime} 9^{\prime \prime}$. Apparent pola distance $83^{\circ} 46^{\prime} 29^{\prime \prime}$. The ephemeris, which was given in Ast. Nachr., No. 3405, requires the correction, according to Prof. Kreuz, of $-3 \mathrm{~m}$. 58s. in R.A. and $-4^{\prime} \cdot 4$ in declination.

\section{SPECIES OR SUBSPECIES?}

$\mathrm{O}^{\mathrm{F}}$ late attention has frequently been called in scientific journals to that rapid multiplication of nominal species of mammals which forms one of the most striking features of the systematic zoology of the last few years. To take an extreme instance: In eastern Europe and northern Asia there exists a pretty little rodent allied to the squirrels, and forming the single Old World representative of the genus Tanias. Until quite recently this creature was supposed to be common to North America, and was generally known as the Asiatic Chipmunk ( T. asiaticus) ; and it is not many years ago that a well-known American zoologist fully recognised the specific identity of the eastern and western forms. Soon afterwards, that very same writer not only separated the American from the Asiatic race, but considered that the former constituted more than a score of distinct species! To take another example. The coyoté, or prairie wolf, has been very generally recognised as constituting a well-marked species distinguished from the ordinary wolf, not only by its inferior size, but by differences of colour and pelage. During the present year Dr. C. H. Merriam, the well-known Government zoologist of the United States, has, however, thought proper to split up the coyoté into a number of what he regards as distinct species. And it may be added that he has done the same for the brown and grizzly bears of his own continent, and also for those of north-eastern Asia.

It is, perhaps, needless to say that this species multiplication is a direct consequence of the increased attention which has been given of late years to the collection and description of mammals ; and that, so far as the actual work itself is con cerned, we have nothing but praise to bestow on the workers. Every one will admit that we ought to know as much as possible about all animals, and that if an American bear. wolf, or stoat can be distinguished from its cousin of the Old World it is right and proper that the differences should be duly recorded. But is it right or advisable to bestow distinct specific names on animals so near to one another that it often requires the aid of a specialist to distinguish the one from the other? No one will deny that the lion and the tiger constitute a couple of well-marked species of the genus Felis. If, however, we trace the Indian tiger westwards into Persia and northwards into Central Asia, we find that it gradually assumes a longer coat, and either increases or decreases in size. Consequently, some zoologists regard the Siberian (and, for what I know, the Persian) tiger as a species distinct from the royal tiger of Bengal. Apart from the question whether the two intergrade in the intermediate area, if this view be adopted, we have now three species instead of two to deal with, namely the lion, the Bengal tiger, and the Siberian tiger; but it will be obvious that the two last differ from one another much less markedly than they both do from the first. If we only use English names, no very great harm is done, for we still see that two forms are tigers, while the other is a lion. In scientific nomenclature the case is, however, different, for each form receives a distinct specific name under the generic title of Felis; and hence there is no means of knowing by the nomenclature alone that two of the three are intimately related, while the other is widely different. Consequently, when we meet with the names Felis tigris and, say, Felis sibirica, and are told that the former is confined to India, we lose sight of the very important fcat that essentially the same type of animal ranges from Ceylon and India to the arctic tundras of Siberia; the difference in the length and thickness of its fur being obviously adaptations to its different climatic surroundings.

Precisely analogous instances occur in the case of the wolves and bears. The wolf of Europe is closely allied to the large American wolf, and very distinct from the coyoté, but if we separate the European wolf as one species, make several of the large American wolves, and several more of the coyoté, we have no clue to their mutual resemblances or differences; and we thus miss much important information about geographical distribution which ought to be apparent at first sight. Take, again, the deer allied to the red deer. The latter (Cervus elaphus) is a very distinct species confined to the Old World. In America it is represented by the wapiti ( $C$. canadensis), which differs in colour, voice, and the form of its antlers. But there exists in Central and North-eastern Asia a deer so closely allied to the wapiti, that from the characters of the antlers alone the two cannot be separated. Now, if we regard this deer as a distinct species, under the name of C. eustephanus, we have obviously no means of knowing that it is much more nearly related to the wapiti than it is to the red deer, and we also lose sight of the circumstance that whereas the group to which the latter belongs is confined to the eastern hemisphere, the wapiti group is common to the north and north-eastern portions of both hemispheres.

But this is not all. By using specific terms in a wide sense the amateur zoologist and sportsman is able to keep in touch with the working zoologist, and thus to participate largely in the more important discoveries and advances of the science; whereas when specific distinctions are made on the minute differences now in vogue, he is utterly at sea, and probably throws up the whole study. Very likely the pure systematist may say that this is a matter of no moment, although this is not our own view.

What may be called the revolt of the amateur and sporting naturalist against the undue splitting of the modern specialist, has been initiated by $\mathrm{Mr}$. Theodore Roosevelt, in an article in our contemporary Sicience for April 30 , under the title of "A Layman's Views on Specific. Nomenclature." Mr. Roosevelt, who holds the important office of President of the Board of Police Commissioners of New York, modestly styles himself a "layman," although he is really a very accomplished field naturalist, and probably knows more about the big game of North America than any other man. In this article the arguments are temperately, lut forcibly put, the author laying stress on some of the points alluded to above, and urging that in the case of closely allied forms varietal or subspecific names should be employed in place of specific ones. Thus, the Asiatic wapiti should be a subspecies of the true wapiti, when its name (Cervus canadensis eustephanus) would at once indicate ts relalionship. With regard to the use of specific names for what are essentially modifications of one and the same type of animal, Mr. Roosevelt writes as follows. "New terminology is a matter of mere convenience, and it is nothing like as important as the facts themselves. Nevertheless terminology has a certain importance of its own. It is especially important that it should not be clumsy or such as to confuse or mislead the student. Although species is a less arbitrary term than genus, still it remains true that it is more or less arbitrary. If one man chooses to consider as species what other men generally agree in treating merely as varieties, it is unfortunate, both because the word is twisted away from its common use, anc

NO. I 446 , VOL. 56$]$ 
further because it confuses matters to use it in a new sense to the exclusion of the word commonly used in that sense. Moreover, it is a pity, where it can be avoided, to use the word so that it has different weights in different cases."

After calling attention to the great confusion and difficulty caused by the multiplication of species in genera which, in any case, contain a large number of specific forms, Mr. Roosevelt proceeds to make some very important remarks concerning genera which contain only one or two forms. He observes that " The points of resemblance between beasts like the wolverines, the beavers, and the moose of the two nurthern continents are far more important than the points of difference. In each of these cases it does not much matter whether these animals are given separate specific rank, because in each case the Old World and the New World representatives make up the whole genus; but even here it would seem to be a mistake to separate them specifically unless they are distinguished by characters of more than trivial weight. The wapiti and Scotch red deer, for instance, are markedly different, and the differences are so great that they should be expressed by the use of specific terms. If the American moose and the Scandinavian elk are distinguished by specific terms of the same value, then it ought to mean that there is something like the, same difference between them that there is between the red deer and the wapiti; and, as far as our present knowledge goes, this is not so. The wolverines, beavers, and moose of the two continents should only be separated by specific terms if the differences between each couple are of some weight, if they approximate to the differences which divide the red deer and the wapiti, for instance; and I know that even these two may intergrade."

With these sentiments we most cordially agree. Although we may prefer to regard each of the couples referred to as constituting only a single species, the harm done by dividing them is comparatively slight, not only, as $\mathrm{Mr}$. Roosevelt states, because they are the sole representatives of their respective genera, but also from the fact that the members of each pair have the same English title ; thus at once indicating their relationship and distribution.

If it be admitted that it is advisable to distinguish closely related forms from those more widely separated by means of nomenclature, the next question is whether it is preferable to do this by means of subgenera or subspecies. To illustrate this the case of the deer may be cited. By many writers of the present day the genus Cervus is taken to include all the deer furnished with brow-antlers, of which the wapiti is the only American representative. In this sense the genus may be split up into several subgenera, such as the Red Deer and Wapiti group (Cervus), the Japanese Deer group (Pseudaxis), the Fallow Deer group (Dama), the Sambar group (Rusa), and the Swamp Deer group (Rzicerous) If we admit numerous species, we have in the first group the Red Deer (Cervus elaphus), the Barbary Deer ( $C$. barbarus), the Maral ( $C$. marai), the Wapiti ( $C$. canadensis), the Asiatic Wapiti (C. eustephanus), \&c. In the fourth we have the Sambar ( $C$. unicolor), the Equine Deer $(C$. equinus), the Rusa (C. hippelaphus), the Hog Deer (C. porcinus), $\&$ c. Now, in the first group the Red Deer and the Maral are very closely allied, as are the true and the Asiatic Wapiti, and to retain these as species, and at the same time to express their true relationships, it is necessary to restrict the term Cervus to the Red Deer group, and to take the subgenus Strongyloceros for the Wapitis. This entails the raising of Pseudaxis, Dama, Rusa, \&c., to the rank of genera. Similarly the Sambar, Equine, and Rusa Deer must form one subgenus of Rusa, and the Hog Deer a second. But this scheme has the disadvantage of splitting up the brow-antlered, or typical deer (Cervuss) into several genera, which are much more closely related than is Cervus in its wider sense to the other usually accepted genera of the family, such as Alces, Rangifer, Capreolus, \&c. We are, therefore, very little forwarder by this arrangement, by which we also lose sight of the fact that the brow-antlered deer (Cervus) are distributed over the greater part of the two northern con. tinents, as well as India and the Malayan countries. On the other hand, if we adopt subspecies, the Maral becomes a subspecies of the Red Deer, as C. elaphus maral, and the Asiatic Wapiti of the true Wapiti as $C$. canadensis eustephanus, while the Equine and Rusa Deer respectively rank as subspecies of Sambar under the names of $C$. unicolor equinuts and $C$. unicolor hippelaphus. Similarly, the Siberian ranks as a subspecies of the Indian tiger; while the brown and grizzly bears of Kamschatka and North America are ranked as subspecies of the European brown bear (Ursus arctus). Otherwise, the lion must be separated subgenerically from the tiger, and the brown and grizzly bears from the black bears. Which is the simpler, and, to most minds, the most philosophic arrangement, needs no mention!

Of course there are difficulties in such an arrangement, as there are in all sublunary matters ; and in many cases there must and will be great difficulties in deciding as to what amount of difference constitutes a species and what a subspecies. But the same difficulty occurs when the term species is used in a more restricted sense. And it may be mentioned that even when so employed, subspecies are recognised by American writers. If it be necessary to indicate such " sub-subspecies," quadrinomials must apparently be employed, but these need only be mentioned for the benefit of the advanced specialist. The unfortunate thing in the matter is the existence of the "personal equation," which is one very difficult to get over. If, however, it be borne in mind when we have a large genus containing a number of welldefined types, around all or many of which cluster a series of closely related forms, that the term species be restricted to the former, while the latter are classed as subspecies, there ought in most cases to be no very great difficulty. In such an arrangement the amateur and the popular naturalist, as well as the student of geographical distribution in its wider and more important sense, can confine himself to the species, while the specialist can busy himself about the subspecies, or even the "sub-subspecies."

Possibly a greater latitude may have to be allowed to the students of the smaller mammals, such as the rodents, in which species may have to be based on slighter differences than are taken cognisance of in the case of the larger forms. Although perfect uniformity would be desirable, it is by no means absolutely essential that the same standard of distinction should be applied to all the groups.

As might have been expected, Dr. Merriam, one of the great champions of "splitting," has not allowed Mr. Roosevelt's challenge to pass in silence. And he has published a reply in Science of May 14, under the title of "Suggestions for a New Method of Distinguishing between Species and Subspecie.." And here a moment's digression may be made to compliment both writers on the good feeling displayed in their criticismsa marked contrast to some Transatlantic scientific disputations. Dr. Merriam states that hitherto he has taken the following as the distinction between species and subspecies, viz. that "Forms known to intergrade, no malter how different, must be treated as subspecies and bear trinomial names; forms not known to intergrade, no matter how closely related, must be treated as full species and bear binomial names." This is, of course, one of those hard-and-fast rules which look very nice on paper, but are not consonant with nature's system; for it is merely an accident whether the intermediate link is still existing, or has died out at a more or less remote epoch. In his new communication Dr. Merriam, for the first time, recognises the unimportance of the survival or extinction of the connecting link, and views with approval the proposal that our choice of binomial or trinomial nomenclature is to be governed by the degree of differentiation rather than intergradation. He expresses his new view as follows, viz. "In my judgment, forms which differ only slightly should rank as subspecies even if not known to intergrade, while forms which differ in definite, constant and easily recognised characters should rank as species even if known to intergrade."

It was not, of course, to be expected that Dr. Merriam would forthwith strike his flag, and admit that $\mathrm{Mr}$. Roosevelt is right and himself wrong, but the giving up of the bugbear "intergradation" as a factor in the question at issue is undoubtedly a great point gained on the side of the "lumpers." It is, in fact, a clear admission that both species and subspecies are pure abstractions in the case of large genera, and that whether an animal is called one or the other is simply a matter of convenience. This being so, we may hope for the future to hear no more about such a creature being a "good" species.

The question of the distinction between species and subspecies is undoubtedly one bristling with difficulties, and it is therefore one which in many cases is incapable of being definitely settled by an individual opinion. Although personally convinced of the advisability of using specific names in a wide sense, and employing trinomials for the designation of the nearly related forms, it may be suggested that an international conımittee of zoologists should be formed to discuss the question

NO. I 446, VOL. 56] 
in all its bearings. Needless to say, such a committee should include representatives of both the "splitting" and "lumping" interests; and if the points at issue were fairly debated, with a full determination to give and take on both sides, it is diffcult to believe that a working compromise between the extreme views could not be arranged. Almost anything is better than the present condition of uncertainty and discrepancy.

R. LYDEKKER.

\section{RECENT INVESTIGATIONS INTO THE NUMERICAL VALUE OF \\ "THE MECHANICAL EQUIVALENT."}

THE value of the "mechanical equivalent," when deduced from experiments based on the direct transformation of mechanical work into heat, affords the best standard by means of which to test the validity of our system of electrical units. It is evident, however, that the value of this test depends upon the accuracy of the "equivalent" determinations. The engineer may (very rightly) regard extreme numerical accuracy in this case as comparatively unnecessary, but from the physicist's point of view there are few natural constants whose exact determination is of equal importance. ${ }^{\text {. }}$

Until the present time the evidence available has been so conflicting that it has been impossible to draw any certain conclusions from a comparison of the heat developed by mechanical work with that resulting from work electrically performed.

In Phil. Trans. Roy. Soc., I893, I gave an account of an investigation, by electrical methods, into the capacity for heat of water. The chief object of that work was to apply to the electrical units the test above referred to, for I considered that Rowland's admirable series of experiments (Proc. American Academy, I879) on the direct conversion of mechanical energy supplied sufficient data to render such an investigation desirable. I regret, however, to say that, for the following reason, the results of that work have hitherto been of little value for the particular purpose for which it was undertaken. The change in the capacity for heat of water indicated by Rowland differed materially from that obtained by means of the electrical experiments. This difference in the rate of change must be due to differences in temperature measurements. In Phil. Trans., I893, p. 496, I wrote as follows: "No change in the value of the various units or constants involved in our in

vestigations could bring our results into absolute agreement with those obtained by Rowland, since, owing to the difference in the expressions for the temperature coefficients for the specific heat of water, it is inevitable that if our conclusions should agree at some one temperature, they must necessarily differ when expressed in terms of a thermal unit at any other temperature, and thus changes in the values of the units would only alter the temperature of agreement."

This quotation will, I think, render evident that but little progress could be made until some explanation of the discrepancies in the temperature measurements was forthcoming.

An indirect comparison of Rowland's standard with that of the Bureau International is given in Prof. Schuster's paper on the "Scale value of Dr. Joule's thermometers" (Phil. MTag., I895). The results indicate that Rowland's rate of decrease in the heat capacity of water would be diminished if expressed in terms of the International Standard; but, as Prof. Schuster remarked, "it would be necessary to have further information before any definite conclusions could be drawn."

I am glad to say that we are now in possession of the further information sought for by Prof. Schuster, and the above brief statement of our difficulties has been made in the hope of drawing attention to the new light now thrown on the whole subject.

1 It has been decided (see Report of the Electrical Standards Committee, 1896) that the thermal unit is to be a dynamical one, hence the demaind for accuracy becomes insistent.

NO. I 446 , VOL. 56]
Two entirely distinct investigations have just been brought to a successful conclusion in the laboratory of the Johns Hopkins University.

(I) "A recalculation of Rowland's value of the mechanical equivalent of heat in terms of the Paris hydrogen thermometer," by W. S. Day.

(2) "A comparison of Rowland's mercury thermometer with Griffiths' platinum thermometer," by C. W. Waidner and F. Mallory.

Both the above investigations have been carried out under the directions of Profs. Rowland and Ames. Full particulars of the work will shortly be published in America; but, in the meantime, the authors have very kindly given me permission to publish the results in this country. I will here give no details beyond the statement that the comparison of Rowland's thermometers with those of the Bureau International were made under conditions as nearly as possible similar to those prevalent during Rowland's experiments, and the same remark holds good with regard to the comparison with the platinum standard.

The results of these entirely separate investigations may be briefly summed up as follows:-

(I) The values resulting from Rowland's experiments undergo considerable modification at certain temperatures.

(2) Over the temperature range covered by Griffiths' experiments $\left(14^{\circ}\right.$ to $26^{\circ} \mathrm{C}$.), the rate of change in the capacity for

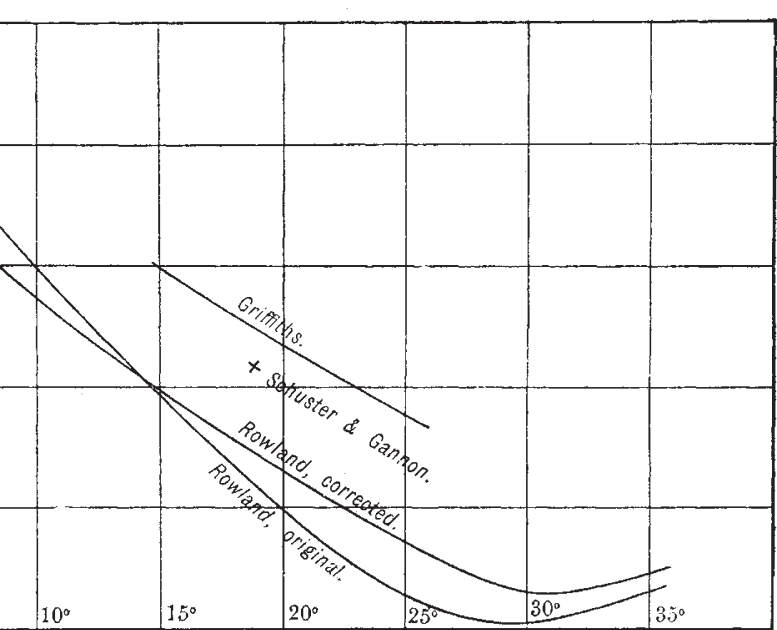

teMPERATURE ON THE PARIS hYDROGEN SCALE.

heat of water becomes practically identical with that given by Griffiths.

(3) Throughout this range, Griffiths' value exceeds Rowland's by about $\mathrm{I}$ in 420 .

(4) Separate standardisations of the same platinum thermometer were performed both in England and in America. The units adopted in the two cases differed slightly, but this is unimportant, as the temperature measurements are independeni of the magnitude of the unit. The essential point is the respective values of the ratio of the resistance at $100^{\circ} \mathrm{C}$. to that at $0^{\circ}$. These were as follows:

$$
\begin{array}{llllll}
\text { English } & \ldots & \ldots & \ldots & \ldots & =\mathrm{I} \cdot 38596 \\
\text { American } & \ldots & \ldots & \ldots & \ldots & =\mathrm{I} \cdot 38597
\end{array}
$$

Thus affording satisfactory proof that not only the electrical measurements, but also the barometric standards, \&c., are in perfect agreement.

(5) The results of the comparison with the platinum standard are (in the words of the authors) "in almost absolute agreement" with those deduced by Mr. Day from the direct com. parison with the international standards, and thus the validity of Callendar and Griffiths' method of standardising the platinum thermometer is confirmed.

In the reduction of Rowland's results, " each individual experiment, the thermometers used in it, and the number of observations made with each thermometer, were taken into account. 